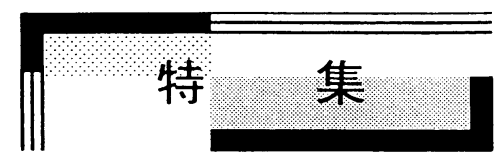

\title{
製鋼プロセスにおける液ノ液系の混相現象*
}

\section{Multi-phase Flow of Liquid/Liquid System in Steelmaking Process}

\author{
北 村 信 也** \\ KITAMURA Shin-ya
}

\author{
瀬 々 昌 文*** \\ ZEZE Masafumi
}

\author{
中 島 潤 二*** \\ NAKASHIMA Junji
}

\begin{abstract}
Steelmaking process consists of refining and solidification. In refining process, the impurity elements are removed by chemical reaction between slag and molten steel, mainly. To improve the reaction rate, the emulsion of fine steel droplets in slag is a useful measure. Solidification is mostly conducted by continuous casting process. In this process, lubrication between the solidification shell and mold is important and the molten oxide (mold flux) is added on the surface of molten steel. However, the entrainment of the mold flux causes the defects of the products. Many researches have been conducted in this field to clarify the multi-phase flow between molten oxide and steel. In this paper, the emulsion phenomena of molten metal in slag and entrainment of oxide in continuous casting processed are reviewed.
\end{abstract}

Keywords: Steelmaking, Slag and metal reaction, Continuous casting, Entrainment of mold flux

\section{1. 緒 言}

製鋼プロセスでは、高炉で鉄鉱石を還元して生 成された溶銑から、炭素、硫黄、りん等の不純物 を精錬除去し、次工程で圧延しや寸い形状の中間 成品として凝固させている。精錬は、主に転炉と 称される反応炉を用いた酸化反応で、酸素ガスを 上方から吹き付けるか、炉底から吹き込むととも に、生石灰や鉄鉱石等を添加してスラグを生成さ せている。また、転炉だけでは高純度化に対応で きないため、転炉精錬の前後で、様々な方式の溶 銑予備処理や 2 次精鍊が広く用いられている。い ずれの反応炉においても、スラグと溶鋼間の不純 物分配が主な反応になるため、液／液系の混相現 象が生じている。特に、スラグ／溶鋼界面を通過 する気泡によるエマルジョンの形成は反応界面 積の拡大につながるため、多くの研究がある。一 方、凝固は、ほとんどの場合が連続鋳造でおこな われているが、割れ等の欠陥がない鋳片を高速で
鋳造するために様々な工夫がなされている。特に、 薄い凝固殼と鋳型との間の潤滑は重要で、そのた めモールドフラックスと呼ばれる酸化物を鋳型 内溶鋼表面に添加・溶融させている。このフラッ クスが溶鋼内に巻き込まれると鋳片欠陥になる ため、それを抑制する研究が多く行われているが、 これも液/液系の混相現象である。本稿では、製 鋼プロセスにおける代表的な液/液系混相現象 である、底吹きガスによるエマルジョンの形成 （執筆担当：北村信也）と、モールドフラックス の巻き込み（執筆担当: 瀬々昌文、中島潤二）に ついて解説する。

\section{2. 底吹きガスによるエマルジョンの形成}

反応界面積を増加させる有効な手段にエマル ジョンの形成があり、攪拌羽根による機械攪拌や、 インジェクションによりフラックス（スラグ）を メタルに懸濁させる技術が用いられている。しか し、溶鉄に懸濁したスラグは容易に浮上分離され、

\footnotetext{
* 2016.8.19 受付

** 東北大学多元物質科学研究所 $\bar{T} 980-8011$ 仙台市青葉区片平 2-1-1

TEL: (022)217-5144 FAX: (022)217-5144 E-mail: kitamura@tagen.tohoku.ac.jp

*** 西日本工業大学工学部 総合システム工学科
} 
安定したエマルジョンを形成するのは困難であ る。一方、転炉、溶銑予備処理、溶融還元などで はスラグに多くの粒鉄が懸濁している事が良く 知られており、非鉄製錬ではスラグに懸濁したス パイス（地鉄）の分離に多大な努力がなされてい る。つまり、溶融金属粒がスラグへ懸濁した場合 は非常に分離され難く、これを反応界面積向上の シーズに利用する事が考えられている。

製鋼分野でも、気泡通過時のメタルのスラグヘ の賏濁については、いくつかの研究があり、液滴 生成機構や物性の影響、䀣濁量の推定式等に関す る知見がある。Fig. 1[1]はスラグ／メタル界面を 気泡が通過する時の現象を整理したものである が、気泡周囲に生成したメタル液膜の破裂や、気 泡の下部に生成したメタル柱の破壊によってエ マルジョンが生成すると考えられている。

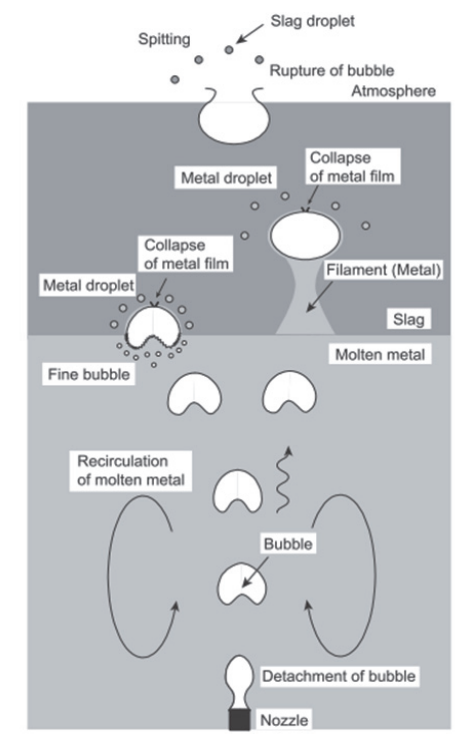

Fig. 1 Schematics of emulsion formation mechanism by rising gas bubble [1]

メタルエマルジョンは、気泡が界面を通過する 時に、その周囲にメタル膜を伴ってスラグ相に侵 入するために生成されるが、Minto ら[2]は、マッ 卜ノスラグ系でのエマルジョン生成に対してフ イルム係数 $(\Theta$; 式 $(1))$ 、浮上係数 $(\Phi$; 式 $(2))$ を定義し、フィルム係数 $\Theta$ が 0 以下で、浮上係 数 $\Phi$ が 0 以上の場合に、界面でメタル膜が崩壊 して生成した粒子の一部が、気泡に付着したまま 浮上しエマルジョンを生成するとしている。

$$
\Theta=\gamma_{s}-\gamma_{m}-\gamma_{m s}
$$

$$
\Phi=\gamma_{s}-\gamma_{m}+\gamma_{m s}
$$

Gammal ら[3]はこれを溶鋼／スラグ系で検討 し、丹は寸べての組成で 0 以下であり、 $\Phi$ も表面 活性成分である硫黄をスラグやメタルに添加し ても 0 以上であるため、ほとんどの場合はエマル ジョンが形成されるが、 $\mathrm{Ti}$ と $\mathrm{TiO}_{2}$ の濃度が高い 場合に 0 以下になる可能性もあるとしている。

一方、Reiter ら[4,5]は水/水銀／油を組み合わ せたモデルでビデオ観察により気泡が界面で破 泡した時に発生寸る液滴に関して研究している。 この実験では、上下相の密度比、粘度比や界面張 力を変化させ、決められた大きさの気泡を浮上さ せ、界面通過時の気泡や液滴の軌跡を詳細に調べ ている。その結果を、平均液滴径と気泡径の比 $\left(r d^{*}\right) 、 1$ 個の気泡により発生した液滴総体積と 気泡体積の比 $\left(V_{d}{ }^{*}\right)$ で整理し、各物性值と気泡 エトベス数 $\left(E_{O b}\right.$ : 式(5)) を用いた無次元を導出 した。

$$
\begin{gathered}
r_{d}^{*}=1.4\left(\frac{\gamma_{m s}}{\gamma_{m}}\right)^{1.6}\left(\frac{\rho_{s}}{\rho_{m}}\right)^{1.2} E o_{b}^{-0.15} \\
V_{d}^{*}=0.13\left(\frac{\rho_{s}}{\rho_{m}}\right)^{1.7} E o_{b} \\
E o_{b}=\frac{g \rho_{s} r_{b}^{2}}{\gamma_{m}}
\end{gathered}
$$

Lin ら[6]も $\mathrm{ZnCl}_{2}$ を添加して比重を変えた水溶 液とシリコン油系で実験を行い、1 個気泡から発 生する液滴総体積 $\left(V_{d}{ }^{0} ; \mathrm{m}^{3}\right)$ に対して式(6)を得 ている。

$$
\begin{aligned}
V_{d}^{0}=1.04 \times 10^{-6}\left(\frac{\mu_{m}^{2}}{\rho_{s}^{2} g}\right)\left(\frac{\rho_{s}^{2} g d_{b}^{3}}{\mu_{m}^{2}}\right)^{0.66} \\
\left(\frac{\mu_{s}}{\mu_{m}}\right)^{-0.34}\left(\frac{\rho_{s}}{\rho_{m}-\rho_{s}}\right)^{1.66}
\end{aligned}
$$

この式に基づき各系での気泡径と液滴発生量 の関係を計算すると、スラグ／メタル系では水モ デルよりもエマルジョンは発生しにくい事がわ かる。

この他、様々な研究者がコールドモデルで液滴 の発生挙動を検討しているが、いずれの研究でも、 
分解能の問題もあり比較的大きなサイズの液滴 を観察対象としている。これに対して、Uemura ら[7]は高分解能の高速度カメラを用いて破泡時 に発生する微細液滴の挙動を観察している。これ らの研究で用いられた水/油系は、物性值を大き く変化させられる利点があるが、粘性や密度が溶 鋼/スラグと大きく異なるため、定性的な理解を 深めるものに過ぎない。

一方、Han ら $[8,9]$ は溶鉄 /スラグの界面をX 線透過法で観察し、また、発生した液滴を界面に 仕切り版を入れて回収し総質量を測定している。 $\mathrm{X}$ 線透過報による観察では、液滴発生の機構は液 膜の後退により気泡中心部から発生する液滴ジ エットによるとしている。また、スラグ組成や界 面活性元素濃度を変化させることで、Fig. 2 のよ うに界面張力が大きいほど、スラグ粘度が大きい ほど液滴総質量は低下しエマルジョンが生成し にくくなる事を示した。これらの結果から、1 個 の気泡により発生した液滴総体積と気泡体積の 比 $\left(V_{d}{ }^{*}\right)$ を気泡エトベス数とモートン数を用い て式(7)で表した。

この方法は、実際の系を用いた実験であるとい う大きな利点があるが、分解能の制約から液滴の
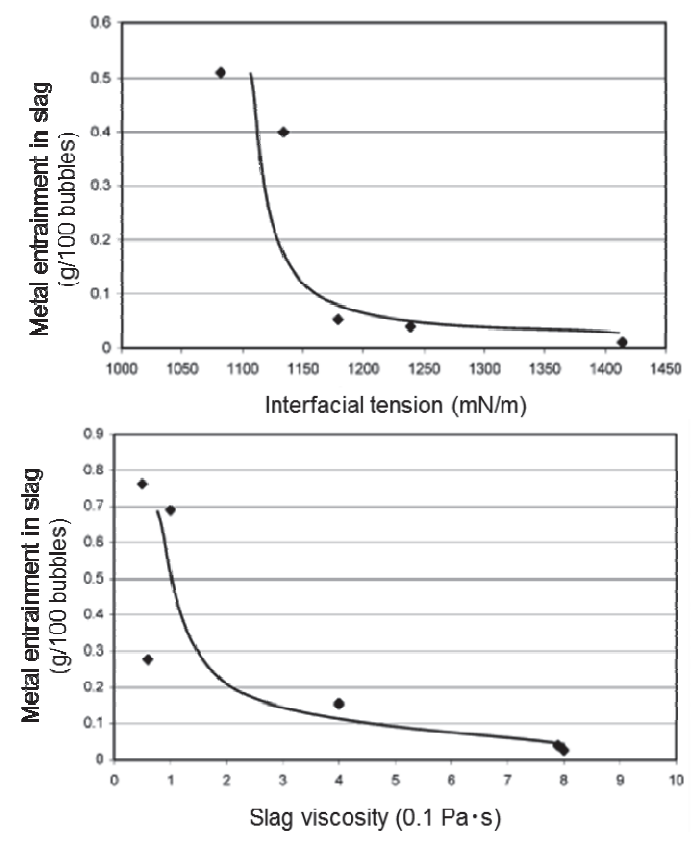

Fig. 2 The influence of interfacial tension and slag viscosity on the metal emulsion [9].
大きさや発生頻度については測定できない。

$$
V_{d}^{*}=0.29\left(\frac{d_{b}^{2.5} g^{1.5} \mu_{m} \rho_{m}}{\gamma_{m s}^{2}}\right)\left(\frac{\mu_{m}}{\mu_{s}}\right)^{0.4}
$$

これに対して、Poggi ら[10]は $\mathrm{Pb}$ と溶融塩 $(\mathrm{KCl}$ 一 $\mathrm{LiCl}-\mathrm{NaCl}$ )を用いた実験を考案している。こ の方法の大きな特徽は溶融塩が水溶性であるた め、上相中の液滴粒子を抽出し、粒径分布を測定 できる点にあり、数 $\mu \mathrm{m}$ から数 $\mathrm{mm}$ の $\mathrm{Pb}$ 粒子を 抽出し、底吹きガス流量の依存性等を論じている が、詳細な粒径分布等には触れられていない。こ の方法を発展させ、Song ら[11-13]は溶融金属を $\mathrm{Pb} 、 \mathrm{Sn}$ 合金、 $\mathrm{Al}$ 合金に変化させ、ガス擋拌中に 溶融塩相から $4 \mathrm{~mm}$ 直径の管で溶融塩試料を採取 し、䀣濁している液滴の粒径分布を測定した。抽 出された液滴粒子は $100 \mu \mathrm{m}$ 以下で、特に $10 \mu \mathrm{m}$ 以下の微細な粒子が非常に多く観察された。また、 ガス擋挥開始から定常に達するまでの液滴総体 積の時間変化や、ガス擋拌終了後の時間変化（沈 降速度）も示し、それらのデータから、液滴発生 速度は時間に依らずに一定であり、液滴沈降速度 は上相中の液滴濃度に比例するという仮定を設 けて、液滴発生速度 $\left(V_{f} ; \mathrm{g} /(\mathrm{min} \cdot \mathrm{g}\right.$-salt $)$ ) を評価 している。その結果、Fig. 3 のように、ガス流量 に対して最大值を持つ傾向が $\mathrm{Al}$ と $\mathrm{Pb}$ では見られ た。定常状態の液滴総質量を比較すると $\mathrm{Al}$ が最 も大きく、 $\mathrm{Sn}$ と $\mathrm{Pb}$ は比重差から予想されるほど の大きな差は見られなかったが、これらの差は Fig. 4 のように気泡の破泡頻度で整理できる事を 示している（ここでMode-A、B は Fig. 1 で示し た気泡破泡時にメタル柱が生成しない場合

(Mode-A）と、生成する場合（Mode-B）に対応 する)。

最近、Yoshida ら $[14,15]$ は溶融 Sn に Teを添加 する事で界面張力の影響を調べるとともに、上記 のサンプリング法では捉えられない、 $100 \mu \mathrm{m}$ 以上 の粒子の発生状況を高解像度の高速度カメラを 用いて評価している。その結果、界面張力の低下 は、破裂時の気泡径が小さくなるためと、メタル 柱が安定化するためにメタルエマルジョンの発 生が抑制される事を示した。さらに、サンプリン グ法で評価した $100 \mu \mathrm{m}$ 以下の液滴粒子と、解像 度が異なる 2 種類のカメラで観察した、 $100 \mu \mathrm{m} \sim$ 
$1 \mathrm{~mm} 、 1 \mathrm{~mm}$ 以上の液滴粒子の発生速度を比較し、 微細粒子の方が発生個数は多いが、総体積では粗 大粒子の方が大きい事を示している。

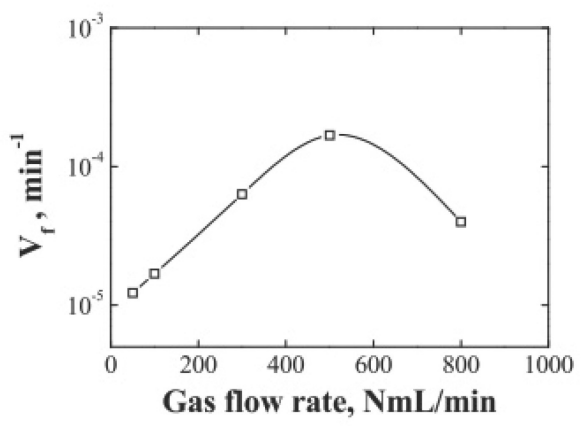

Fig. 3 Influence of stirring gas flow rate on the formation rate of metal emulsion in $\mathrm{Al}-\mathrm{Cu} / \mathrm{slat}$ system [12].

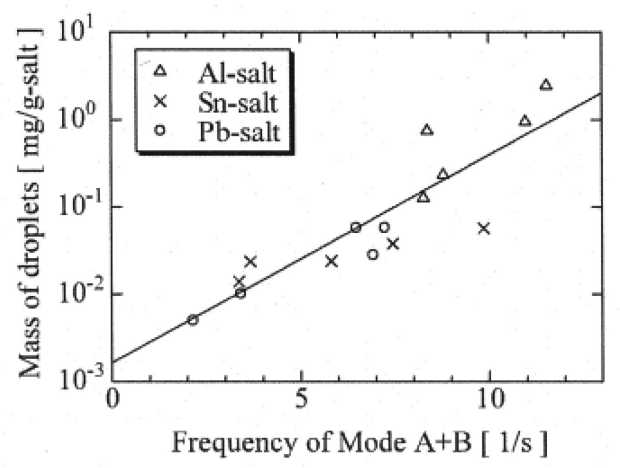

Fig. 4 The relation between total mass of droplets in the salt phase and bubble rupture frequency [13].

Liu ら[16-18]は、上相を溶融塩の代わりに、粘 性が製鋼スラグに近く、かつ低融点で水溶性であ るとともに透明である $\mathrm{Na}_{2} \mathrm{~B}_{2} \mathrm{O}_{4}$ として Song らと 同様の実験を行っている（この場合、サンプラー を $14 \mathrm{~mm}$ 直径の管にして多量の上相を採取して (る)。その結果、Fig. 5 に示すように溶融塩に 比べて大きな液滴が観察されている。これは液滴 の沈降速度が粘性に大きく依存するためと考え られる。また、Song らと同様な方法で液滴発生 速度 $\left(V_{f}{ }^{\prime} ; \mathrm{g} /(\mathrm{min} \cdot \mathrm{g}\right.$-oxide $\left.)\right)$ を評価して、同一の 観察粒径範囲 $(100 \mu \mathrm{m} \sim 1 \mathrm{~mm})$ で、高解像度カメ ラで観察された溶融塩系での值と比較した結果、
粘性の大きい酸化物系の方が液滴発生速度は小 さいという結果を得た。
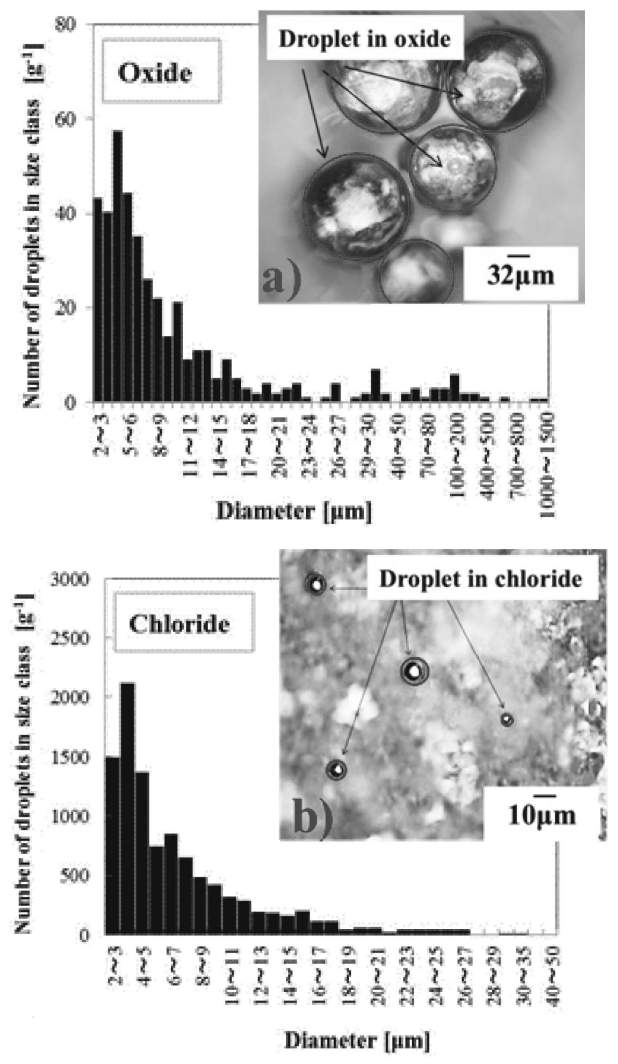

Fig. 5 Size of the sampled droplets in oxide comparing with those in salt [16].

さらに、上記粒径範囲を対象として、1 個の気 泡により発生した液滴総体積と気泡体積の比

$\left(V_{d}^{*}\right)$ を、物性值とエトベス数で整理し式(8)を 導出した。

$$
V_{d}^{*}=2.9 \times 10^{-5}\left(\frac{\gamma_{m s}}{\gamma_{m}}\right)^{-1.89}\left(\frac{\mu_{s}}{\mu_{m}}\right)^{-1.34} E o_{b}^{1.27}
$$

以上のように、多くの製鋼プロセスを対象にし たエマルジョンの研究が報告されている。エマル ジョンの形成には密度比、粘性（特に上相）、界 面張力の影響が大きいと考えられるが、すべてを 実際のスラグ／溶鋼系に合わせる事はできない ため、実験結果の適用範囲は十分に注意を要する。

このうち、粘性の影響については Han ら [9]、 
Lin ら[6]、Liu ら[17]のいずれもが粘性が低下する 方がエマルジョンの生成速度は増加するとして いる。界面を気泡が通過する時の粘性力の影響と 考えられているが、粘性が小さい場合には逆に液 滴の沈降速度が大きくなるため、定常状態でのエ マルジョン量を最大にする、粘性の適正值が存在 寸る可能性がある。一方、界面張力の影響につい ては、Han ら[9]と Liu ら[17]では反対の結論にな っている。界面張力はエマルジョン生成だけでな く、破泡時の気泡径にも大きな影響を与えるため、 今後の検討が必要である。

ところで、1 個の気泡で生成した液滴全体積と 気泡体積の比に対しては、式(4)、(6)、(7)、及び 式(8)が提示されている。これをスラグ／溶鋼の物 性で計算した結果を Fig. 6 に示すが、大きな差が ある(ここで、式(6)に対しては気泡径を $8.5 \mathrm{~cm}$ と して計算した)。これは、それぞれの実験式で適 用できる液滴や気泡のサイズ範囲や物性值範囲 が違うためである。

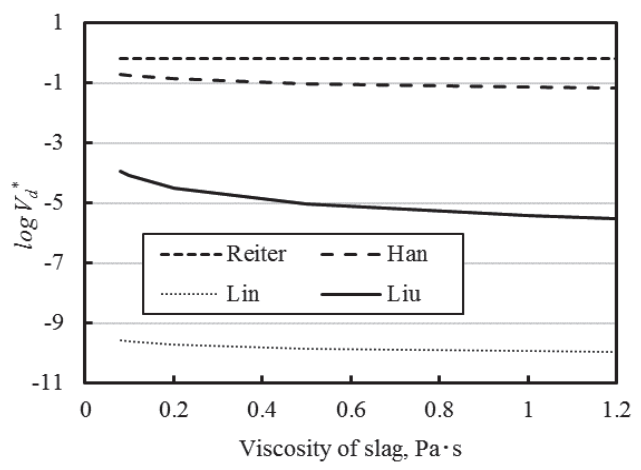

Fig. 6 Comparison of dimension less equation, which estimates the ratio of total volume of droplets and bubble volume.

このように、精鍊プロセスにおけるエマルジョ ンの生成は、多くの研究があるものの未解明の部 分も多く、「制御して利用する」までには至って いない。

\section{3. モールドフラックスの巻き込み}

モールドフラックス (パウダー) は初期凝固殼 と鋳片との間の潤滑の他にも様々な役割を担っ ているが、溶鋼中に巻き込まれて鋼材中に残存す ると、有害介在物として鋼材品質を大幅に損ねる
ことになる。とくに生産性の向上を目的として高 速鋳造を志向した場合には、鋳型内の溶鋼流動が 大きくなるとともに不安定にもなるため巻き込 みや寸くなり、鋼材品質への影響は顕著になる。

溶鋼中に䀣濁し浮上除去されることなく鋼材 中に残存したモールドフラックスは $\mathrm{Ca} 、 \mathrm{Si} 、 \mathrm{Al}$ を主成分とし $\mathrm{Na} 、 \mathrm{~F}$ を含有する酸化物である。 種々の原因で巻き込まれたモールドフラックス が初期凝固殼に捕捉された場合、鋼材が圧延され るにしたがって、製品表層に露出して線状の疪と なる。また、鋳型下部に向かう流れに従って粗大 なモールドフラックスが鋼材内部に捕捉された 場合、製品表層には露出せず、製品が加工される 段階、例えば薄板のプレス成型時に割れの起点と なり、孔が空く等の不具合が発生する場合がある。 一般に、問題となる巻き込まれたモールドフラッ クスの大きさは製品の加工度が大きいほど小さ くなる傾向があり、許容限界となる大きさは鋼材 の用途により異なる。

モールドフラックスの巻き込み機構について は従来から多くの研究[18-20]がなされており、井 口ら[19]は以下のように分類している。

(1)定常反転流による削り込み(1)

(2)カルマン渦による巻き込み(2)

(3)上昇するアルゴン気泡が湯面を擾乱するこ とによる巻き込み(3)

(4)急激なせん断流による巻き込み(4)

(5)浸漬ノズル表面での非定常圧力差による巻 き込み(5)

(6)浸漬ノズルに沿って上昇するアルゴン気泡 の湯面への衝突による巻き込み

(7)浸漬ノズルに沿って下降するモールドフラ

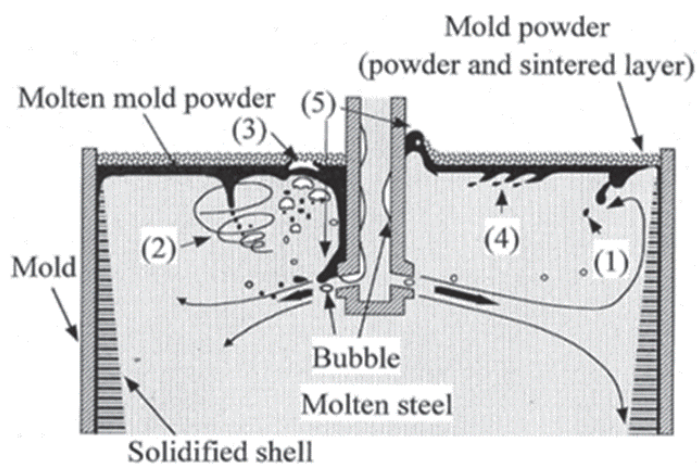

Fig. 7 Previously proposed mechanisms of mold flux entrapment [19]. 
ックスの巻き込み

Fig.7 に主な機構である(1)〜 (5)を模式的に示す。 このうち(1)、(2)、(3)、(4)、(6)は湯面すなわちモー ルドフラックス／溶鋼界面で巻き込みが起こる ため湯面での溶鋼流動と密接な関係を持つ。

浅井[21]は、モールドフラックス（スラグ）／ 溶鋼界面でスラグが巻き込まれる際の慣性力、浮 力、界面張力とのエネルギーバランスを式(9)のよ うに考え、巻き込まれたスラグ滴の半径が実数值 をとる条件から、巻き込み限界流速 $V_{c r}$ として式 (10)を導出している。

$$
\frac{1}{2} \rho_{s}\left(\frac{4}{3} \pi r_{s}^{3}\right) V_{s c r}^{2}=4 \pi r_{s}^{2} \gamma_{s m}+g\left(\rho_{m}-\rho_{s}\right)\left(\frac{4}{3} \pi r_{s}^{3}\right) r_{s}
$$

$$
V_{c r}=\sqrt[4]{\frac{48 g \gamma_{s m}\left(\rho_{m}-\rho_{s}\right)}{\rho_{s}^{2}}}
$$

巻き込み限界流速は、界面張力と密度差が大き くなるほじ大きくなり、巻き込まれ難くなること がわかる。しかし、式(9)にはスラグ（モールドフ ラックス）の粘度に関する項がなく、粘度の影響 を評価することはできない。

大塚ら[22]は、浅井の式を基にモールドフラッ クスが巻き込まれる際の界面での粘性摩擦力を 考慮した式(11)を導出している。

$$
\begin{aligned}
& \frac{1}{2} \rho_{s}\left(\frac{4}{3} \pi r_{s}^{3}\right) V_{s c r}^{2}+g H \rho_{s}\left(\frac{4}{3} \pi r_{s}^{3}\right)= \\
& 4 \pi r_{s}^{2} \gamma_{s m}+g\left(\rho_{m}-\rho_{s}\right)\left(\frac{4}{3} \pi r_{s}^{3}\right) R_{s}+\frac{4 \pi r_{s}^{2}}{2} \mu_{s}\left(\frac{\Delta V_{s}}{\Delta z}\right)
\end{aligned}
$$

ここで、 $V_{s}$ はスラグの速度、 $z$ はスラグ／溶鋼 界面からの距離、 $H$ はスラグが巻き込まれるとき の湯面変動、 $\Delta V_{s} / \Delta z$ はモールドフラックス中 の速度勾配である。式(11)よりモールドフラック スの粘度を増大させると巻き込み限界流速が大 きくなることがわかる。大塚ら[22]の他にも巻き 込み対策としてモールドフラックスの高粘性化 を指向する研究は多い。しかし、巻き込み限界流 速に及ぼすモールドフラックスの粘度の影響に
ついて系統的に調査した研究はほとんどない。

そこで、井口ら[19]は水(溶鋼)ーシリコンオイ ル（モールドフラックス）系の実験装置を用い、 $1 \sim 350 \mathrm{~mm}^{2} / \mathrm{s}(\mathrm{cSt})$ の 6 種類の動粘度のシリコンオ イルの巻き込み限界流速を調査し Fig. 8 のよう な結果を得ている。巻き込み限界流速の実験值と 式(9)の浅井のモデルによる計算值はほぼ一致し ているが、細かくみると低粘度域では実験值は計 算值よりもやや小さく、高粘度域では逆転しシリ コンオイル粘度の影響が現れていることが推察 される。瀬々ら[23]は $10 \sim 1000 \mathrm{~mm}^{2} / \mathrm{s}(\mathrm{cSt})$ の 6 種 類の動粘度のシリコンオイルを用いた同様の実 験を行い Fig. 9 のような結果を得ている。井口ら [19]の結果よりも巻き込み限界流速に及ぼすシリ コンオイル粘度の影響が大きく表れている。また、 水側に界面活性剤を添加することで、シリコンオ イル／水間の界面張力を小さくした実験も行っ ており、界面張力が小さくなると巻き込み限界流

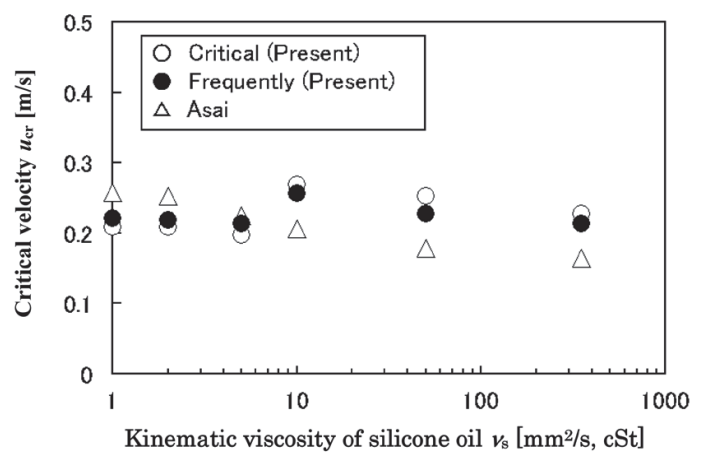

Fig. 8 Critical entrapment velocity [19].

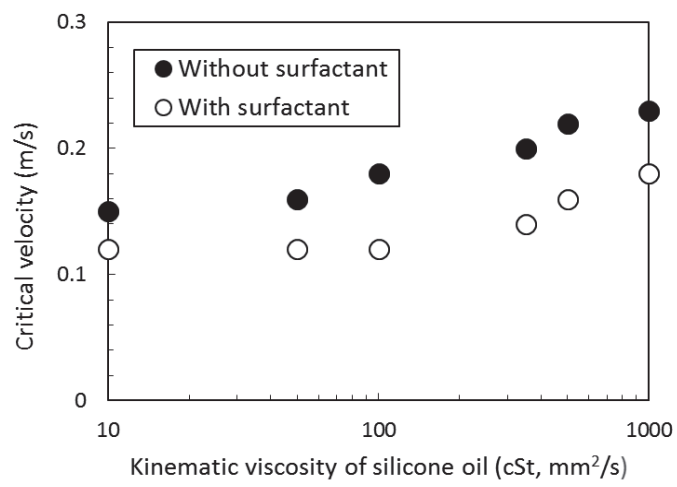

Fig. 9 Effect of oil viscosity and oil/water interfacial tension on critical entrapment velocity [23]. 
速が小さくなることも示されている。両者の差は シリコンオイル上面の拘束条件であり、モールド フラックス上面の拘束条件や溶融厚みの影響に 関しても詳細な検討が必要と思われる。また、モ ールドフラックス/溶鋼系のように密度の異な る流体が積み重なったいわゆる密度成層流体で は、流体間に相対速度差が生じるとケルビンーへ ルムホルツ不安定と呼ばれている界面の不安定 現象が起こる。これは(4)のせん断流による巻き込 みと関連付けられ、界面が不安定になる限界速度 は式(12)で表される。

$$
\left(V_{r}-V_{r}\right)_{c r}^{4}=\frac{4 \gamma_{s m} g\left(\rho_{m}-\rho_{s}\right)\left(\rho_{s}+\rho_{m}\right)^{2}}{\rho_{s}^{2} \rho_{m}^{2}}
$$

ここで、 $V_{s} \fallingdotseq 0$ とおけるので、巻き込み限界流 速は、主に界面張力と密度差に依存寸ることにな る。

一方、Fig. 7(2)に示したカルマン渦による巻き 込みについては、渦の発生頻度と渦の深さの観点 から研究された例[24, 25]があり、滑の深さ $D$ は 渦の周速度 $V_{a}$ から求めたエネルギーバランスよ り式(13)で表される。

$$
D=\frac{\rho_{m}}{\left(\rho_{m}-\rho_{s}\right)} \frac{V_{a}^{2}}{g}
$$

渦の深さは溶鋼流速の 2 乗に比例する。

以上のようにモールドフラックスの巻き込み には、鋳型内の溶鋼流動とくに湯面 (メニスカス) での溶鋼流動の影響が大きい。鋳型内の溶鋼流動 の制御については、鋼材品質、操業性、生産性等 を総合的に考慮して最適解を求めることが重要 であり、高谷[26]が総説しているように多くの研 究がなされている。

一方、通常、鋼の連続鋳造では浸漬ノズル内壁 への介在物付着を防止するためにノズル内にア ルゴンガスが吹込まれる。このアルゴンガス気泡 が巨大化して湯面から離脱する際に界面を擾乱 してモールドフラックスを巻き込むのが(3)の巻 き込み機構である。鋳型内のアルゴンガスによる 巻き込み挙動については、様々な研究がなされて おり、難介在物付着ノズルを用いて低アルゴン流 量操業を行いモールドフラックスの巻き込みを
抑制する方法も提案されている[27]。

また、(5)、 (6)、(7)の巻き込み機構は、浸漬ノズ ル耐火物とモールドフラックス、アルゴンガス、 溶鋼との間の濡れが大きく関与する機構であり、 製造現場での実態調查を始めとした今後の更な る研究が期待される。

\section{3. 結 言}

製鋼プロセスで重要な液／液系の混相流現象 として、スラグ/メタル精錬におけるエマルジョ ンの形成と、連続鋳造でのモールドフラックスの 巻き込みについて整理した。いずれの現象も、単 純系での要素実験は数多く行われており、数值解 析によるシミュレーションも多く報告されてい る。しかし、実際の工業プロセスの中では、様々 な要因がからんでいるため、いまだに完全に制御 できている訳では無く、今後も継続して研究がな されていくものと思われる。

\section{謝 辞}

本論文の作成に対する、物質・デバイス領域共 同研究拠点の支援に、感謝の意を表する。

\section{Nomenclature}

$D \quad$ : depth of vortex [m]

$d_{b} \quad$ : diameter of bubble [m]

$r_{b} \quad:$ radius of bubble $\quad$ [m]

$r_{s} \quad$ : radius of entrained slag droplet [m]

$g \quad:$ acceleration of gravity $\quad\left[\mathrm{m} / \mathrm{s}^{2}\right]$

$H \quad$ : movement of interface [m]

$V_{a} \quad$ : peripheral velocity of vortex $\quad[\mathrm{m} / \mathrm{s}]$

$V_{c r} \quad:$ critical velocity of entrainment $\quad[\mathrm{m} / \mathrm{s}]$

$V_{s} \quad$ : velocity of slag $\quad[\mathrm{m} / \mathrm{s}]$

$\mathrm{z}:$ distance from interface $[\mathrm{m}]$

$\gamma \quad$ : interfacial or surface tension $\quad[\mathrm{mN} / \mathrm{m}]$

$\mu \quad$ : viscosity $\quad[\mathrm{Pa} \cdot \mathrm{s}]$

$\rho \quad:$ density $\quad\left[\mathrm{kg} / \mathrm{m}^{3}\right]$

\section{Subscripts}

$m \quad$ : metal phase

$s \quad$ : slag phase

ms : slag/metal interface

\section{参考文献}

[1] Kochi, N., Ueda, Y., Uemura, T., Ishii, T and Iguchi, M., Numerical Simulation on Penetration Stage of a Rising Bubble through an Oil/Water Interface, ISIJ Inter., Vol.51(6), 1011-1013 
(2011).

[2] Minto, R., and Davenport. W. G., Entrapment and Flotation of Matte in Molten Slag, Trans. IMM, Vol. 81(1), C36-42 (1972).

[3] Gammal, T. E., Hinds, G. and Schoneberg, U., Influence of Alloying Elements and Metalloids on the Emulsion and Separation Behavior of Steel and Slag, Steel Res., Vol. 62(4), 152-156 (1991).

[4] Reiter, G. and Schwerdtfeger, K., Observation of Physical Phenomena Occuring during Passage of Bubbles through Liquid/Liquid Interfaces, ISIJ Inter., Vol.32(1), 50-56 (1992).

[5] Reiter, G. and Schwerdtfeger, K., Characteristics of Entrainment at Liquid/Liquid Interfaces due to Rising Bubbles, ISIJ Inter., Vol.32(1), 57-65 (1992).

[6] Lin, Z. and Guthrie, R.I.L., Modelling of Metallurgical Emulsions, Metal. Mater. Trans.B, Vol. 25B(12), 855-864 (1994).

[7] Uemura, T., Ueda, Y. and Iguchi, M., Visualization of Ripples on the Surface of a Rising Bubble through an Immiscible Oil/Water Interface, Journal of Visualization, Vol.15(2), 119-121 (2012).

[8] Han, Z. and Holappa, L., Formation of Metal Droplets from Gas Bubbles Bursting on Iron Melt, Steel Res., Vol.72(11), 434-438 (2001).

[9] Han, Z. and Holappa, L., Characteristics of Iron Entrainment into Slag due to Rising Gas Bubbles, ISIJ Inter., Vol.43(11), 1698-1704 (2003).

[10] Poggi, D., Minto, R. and Davenport, W.G., Mechanisms of Metal Entrapment in Slags, J. Metals, Vol.21(11), 40-44 (1969).

[11] Song. D.Y., Maruoka, N., Maeyama, T., Shibata, H. and Kitamura, S., Influence of Bottom Bubbling Condition on Metal Emulsion Formation in Lead-Salt System, ISIJ Inter., Vol.50(11), 1539-1545 (2010).

[12] Song. D. Y., Maruoka, N., Gupta, G. S., Shibata, H., Kitamura, S., Sasaki, N., Ogawa Y. and Matsuo, M., Influence of Bottom Bubbling Rate on Formation of Metal Emulsion in Al-Cu Alloy and Montel Salt System, ISIJ Inter., Vol.52, 1018-1025 (2012).

[13] Maruoka, N., Song, D. Y., Gupta, G. S., Shibata, H. and Kitamura, S., Behavior Comparison of $(\mathrm{Al}, \mathrm{Pb}, \mathrm{Sn})$ - Molten Salt Emulsion Involving Gas Bubbling, J. JSEM, Vol.14, s200-204 (2014).

[14] Yoshida, H., Liu, J., Kim, S. L., Gao, X., Ueda, S., Maruoka, N. and Kitamura, S., Direct Observation of Formation Behavior of Metal Emulsion in $\mathrm{Sn} / \mathrm{Salt}$ System, Metal. Mater. Trans. B, Vol.47B(8), 2498-2508 (2016).

[15] Yoshida, H., Liu, J., Kim, S. J., Gao, X., Ueda, S. and Kitamura, S., Influence of the Interfacial Tension on the Droplet Formation by Bubble Rupture in $\mathrm{Sn}(\mathrm{Te})$ and Salt System, ISIJ Inter., Vol.56, (2016), (in press).

[16] Liu, J., Maruoka, N., Ueda, S. and Kitamura, S., Metal Emulsion by Bubbling in Molten Tin Oxides System, Proceedings of International Congress on Steelmaking (ICS2015), 862-865, (2015).

[17] Liu, J., Gao, X., Ueda, S., Kitamura S. and Kim, S. J., Influence of Viscosity and Interfacial Tension on the Formation of Metal Emulsion by Rising Gas Bubble, CAMP-ISIJ, Vol.29 (2016), (in press).

[18] Yoshida, J. and Iguchi, M., Mold Powder Entrapment in Continuous Casting Process, Fluid Flow in Continuous Casting Mold and Behavior of Non-metallic Inclusions, 155-239, ISIJ, Tokyo (2002).

[19] Iguchi, M., Nakahata, Y., Zeze, M., Yamamura, H. and Tani, M., Water Model Study of Viscosity Effect on Mold Powder Entrapment, Tetsu-toHagané, Vol.101(11), 559-565 (2015).

[20] Swartz, K., Hibbeler, L., Joyce, B. and Thomas, B., Numerical Investigation of Slag Entrainment, Iron \& Steel Technology, Vol.12(7), 79-90 (2015).

[21] Asai, S., Fluid Flow and Mass Transfer in Metallurgical Processes Where Stirring is Utilized, 100th and 101st Nishiyama Memorial Lecture, 65-100, ISIJ, Tokyo (1984).

[22] Otsuka, Y., Yuyama, H., Kashio, S. and Suzuki, M., Influence of Powder Viscosity on Powder Entrainment in Mold, CAMP-ISIJ, Vol.3, 1225 (1990).

[23] Zeze, M., J. Nakashima and M. Iguchi, Water Model Study of Viscosity and Interfacial Tension Effect on Mold Powder Entrapment, CAMP-ISIJ, Vol.28, 122(2015).

[24] Tanaka, H., Kuwatori, H. and Nishihara, R., Analysis of Continuous Casting Powder Entrapping Phenomena by Water-model Experiments, Tetsu-to-Hagané, Vol.78(5), 761-766 (1992).

[25] Kasai, N. and Iguchi, M., Water-model Experiment on Melting Powder Trapping by Vortex in the Continuous Casting Mold, Tetsu-to-Hagané, Vol.92(9), 544-550 (2006).

[26] Takatani, K., Transition of Steel Flow Control Technology in a Continuous Casting Mold, Tetsu-to-Hagané, Vol.90(10), 751-757 (2004).

[27] Mukai, K., and Zeze, M., Motion of Fine Particles under Interfacial Tension Gradient in Relation to Continuous Casting Process, Steel Res., Vol.74(3) 131-138 (2003). 